\title{
Transformative Education and its Potential for Changing the Lives of Children in Disempowering Contexts
}

\author{
Felix Bivens, Kathleen Moriarty and Peter Taylor
}

\begin{abstract}
For millions of children around the world, disempowerment is not just a part of life - it becomes their life, to the point where any alternative way of living may be unimaginable to them. Intergenerational transmission (IGT) of inequality is deeply embedded, even where education is available; this leads us to question whether many forms of education, experienced by children who are already disempowered, may further entrench that condition by reproducing the norms, values and drivers within society that have brought about this disempowerment in the first place. In this article we explore the extent to which access to good-quality, transformative education has a key role to play in overcoming IGT of marginalised children and their communities, with positive outcomes not only for the individuals themselves but also for wider social processes.
\end{abstract}

\section{The challenge for education}

For millions of children around the world, disempowerment is not just a part of life - it becomes their life, to the point where any alternative way of living may be unimaginable to them. Other articles in this IDS Bulletin highlight a wide range of examples by which children experience inequality, frequently manifesting itself through intergenerational transmission (IGT). Although IGT of a wide range of inequalities is seen most clearly through examples arising in specific contexts, there is no doubt that the IGT of inequality is a global experience. Education - widely understood as a social good and a basic human right which will lead to improved livelihoods of all those who have access to it - has a central role in disrupting the IGT of poverty, inequality and

disempowerment; however, lack of access to education and/or poor quality education can lead to the reproduction of existing inequalities between one generation and the next.

In contexts where education is least accessible and where governments have limited resources and capacity or even the political will to invest in education - for instance in conflict-affected fragile states (CAFS) ${ }^{1}$ - IGT of inequality seems deeply embedded and leads us to question whether many forms of education, experienced by children who are already disempowered, may further entrench that condition by reproducing the norms, values and drivers within society that have brought about this disempowerment in the first place. In this article we explore the extent to which access to good-quality, transformative education has a key role to play in overcoming IGT of marginalised children and their communities, with positive outcomes not only for the individuals themselves but also for wider social processes.

\section{What education aims to achieve}

The Education for All (EFA) movement, which began in 1990 in Jomtien, Thailand, and was reaffirmed in the six EFA goals in Dakar in 2000, continues to be the primary framework for education policy in developing countries. The fundamental goal of EFA is full access to quality education for people of all ages, though the plurality of energy and funding has been devoted to primary and basic education largely due to the parallel influence of the Millennium 
Development Goal (MDG) of Universal Primary Education (UPE) by 2015. Huge gains have been made in increasing access to education for children around the world, although there are still an estimated 75 million children ${ }^{2}$ who are not yet attending school, at least 37 million of whom live in CAFS (Save the Children 2008).

Rapidly expanding enrolments at the primary level have created new difficulties and exacerbated perennial challenges - overcrowded classrooms, shortages of qualified teachers and lack of sufficient learning material - and created new ones: the inability of secondary programmes to absorb enlarged enrolments and, according to the World Bank, students not learning what they should at the primary level, leaving them unprepared for the requirements of secondary curricula (Hanushek and Wößmann 2007). Furthermore, evidence suggests that little correlation has been found between the number of years spent in school and the economic return from schooling for the individual or for the individual's country (DFID 2008).

The discourse on quality has been adopted as a counterpoint to these difficulties: a key idea being that expanding enrolments would not impede student achievement so long as the quality in education remains high. The 'quality imperative' has been given increasing attention in recent years, as a means not only of addressing the challenge of getting children into school but also to try to enhance the educative experience that they have once there. A further intention is to increase completion rates, since poor quality, irrelevant education is often cited by parents and students alike as a reason for dropping out of school. However, the rather generalised understanding of quality emerging so far has been difficult to define and measure in practice.

There are two prominent interpretations of education quality. The first is a humanist understanding that looks primarily for the social development of learners, and is informed by constructionist learning theory derived from the works of Dewey (1916) and Piaget (1955). It adopts a broad definition of quality in education, emphasising the role of education in human development, and placing learners at the centre of the education process. The second interpretation, which we will refer to here as behaviourist/economistic, is more concerned about learners' measurable cognitive development as the major objective of education, and sees the degree to which education achieves this as the indicator of its quality. These two differing interpretations of quality have shaped policy and practice on quality over many years with different international organisations adopting different concepts of quality in education; however, recent analysis suggest that the behaviourist perspective is becoming increasingly attractive to governments and donors alike, looking for quick wins in the drive for improved quality. The idea of 'effectiveness' has also become popular in recent years and focuses on educational 'process' as a key determinant to produce learning outcomes. Essentially quantitative in orientation, the school effectiveness approach, which has strongly influenced the thinking of a number of donors, such as United States Agency for International Development (USAID) and the World Bank, as well as many ministries of education, is concerned about pupils' cognitive achievement demonstrated as test scores, and hence is based on the behaviourist approach to defining quality.

\section{Limitations of the education 'quality' agenda}

There is an extensive literature on educational quality, but there is less evidence for the contribution that 'quality education' has made to the significant changes needed in the lives of children who suffer marginalisation and disempowerment. There appears to be a gap in knowledge about the potential of high-quality education to help reduce the pernicious challenges of injustice, marginalisation and disempowerment such as the examples discussed in other articles in this IDS Bulletin.

Some specific elements of the quality discourse do help to shed light on this complex issue. The 'learner-centred' approach provides a framework that measures education quality as the extent to which the education system meets individual learner's learning needs and processes. Notwithstanding, it appears that both schooleffectiveness studies and learner-centred approaches focus on learners as individuals and generally fail to locate such learners in larger social and global contexts. Neither approach may be sufficient to provide a framework which helps us understand an educational approach whose quality is measured by the extent to which 
learners are empowered or may exert agency upon the prevailing inequity and injustice in their lives and in society.

More evidence is needed, therefore, and there are few empirical research studies to draw upon, although there are some valuable examples. Research in Jamaica (Moncrieffe 2004) has revealed how children who are being socially conditioned in contexts of persistent intrahousehold, state- and community-level violence deal (or fail to deal) with day-to-day violence. The children's stories show: the ways in which different groups among them are stigmatised; their lack of trust in the political process and in state institutions; how violence gets reproduced in families and communities; why and how children become progressively hardened in contexts of violence; and their aspirations and why and how some among them eventually fail to aspire. Many of the children interviewed in this research showed a clear need for individual psychological attention and for education formal and informal - that would help to transform their perceptions of themselves and society's perception of them. Disturbingly, many reported that their negative self-images were reinforced within schools.

Such experiences are not confined to a few, isolated situations. Whether the context is characterised by explicit violence or by other forms of disempowerment and marginalisation (e.g. lower-caste children in India, children of non-Vietnamese-speaking ethnic minorities in Vietnam, or children of Roma and travelling peoples in Europe), schooling is perceived frequently as lacking the potential to enable children to learn for a life based on freedoms; instead, it may be preparing children for a life of limited choices and unfreedoms. Indeed, after so many years of effort to enhance the experience of schooling, it seems astonishing that education is still failing to meet the needs of the very children who need its benefits the most. One explanation for this is that the dominant discourse on effectiveness, which is intensively quantitative and relies heavily on testing and test scores to verify effectiveness and hence quality, has been inadequate and often inappropriate.

The perceived needs for measurement and assessment of learning are powerful drivers in education, influencing for example the World Bank's reliance on rates of return on educational investment. This quantitative framework does not appear to support or promote pedagogical approaches that focus on learner transformation and empowerment, or approaches that engage directly with processes of social change within communities. Although testing produces measurable outcomes that are clear and easily analysed at one level, Goldstein (2004) points out that even high test scores sometimes do not equate with observed learning outcomes among students. Goldstein's research also describes how curricula built around testing outcomes undermine teacher professionalism by necessitating highly structured learning modules that emphasise 'teaching to the test' and leave little room for teacher autonomy and creativity in the classrooms. Consequently, such top-down management of learning also stifles the possibility of creative, spontaneous learning by the students themselves. They have no power to adapt the curriculum to their needs and desires. The lack of participatory space in the classroom is particularly troubling because, as Taylor and Fransman (2004) and others have written, students tend to reproduce the attitudes and behaviours they experience during their formative education; thus top-down educational practices reinforce the perception of students that they are disempowered, unable to influence or shape their environment to meet their needs.

It appears that current approaches to education quality - even if resourced fully - will not lead to inclusion of, or change for, the most marginalised groups or deliver change for children. Continuing to pursue a limited vision of quality will fail to bring about the changes so desperately needed for the most marginalised children in the hardest to reach contexts. Alternatives are needed that can counter the limitations of current trends towards predominantly quantitative education models, but which can build on the strengths of the behaviourist and humanist approaches that inform current thinking on education and schooling.

\section{Looking for alternatives}

It would be unreasonable to suggest that the current models of quality are completely inappropriate. There has been progress, and there is much to value, even though the quality discourse is rather fragmented. There is nothing 
wrong inherently with measurement and testing, since there is no doubt that learning is enhanced when learners understand how they are progressing and appropriate support is then provided. It is important that those who plan and fund education should know to what extent they are contributing to different sets of development goals and aims. A problem lies, however, in the way that a narrow orientation of education towards the cognitive, the behavioural and ultimately the economistic, manifested through over-reliance on testing and measurement, is disabling its potential to bring about significant change within individuals and within society more widely. A consequence of this appears to be a dissociation of educational institutions and students from their local realities. This leads us to ask what alternative approaches exist that can be integrated feasibly and practically into current educational systems and practice?

Humanist approaches in education do seem to help 'round out' the narrow focus and limitations of the behaviourist-economist approach. While not free from statistical assessment, there is a complementarity arising from the best of the behaviourist and humanist approaches that could provide space for more creative, student-focused pedagogies. Clearly this is valuable for all students, regardless of the context in which they live, but the question still remains as to whether this would be sufficient to address the deep and intransigent inequalities that are transmitted intergenerationally. If the lives of children are to be positively transformed, then what kind of education could help to bring this about? A shift does seem needed, and such a shift can, we believe, be achieved by an integration of 'transformative learning theory and practice' within existing education approaches. This view is informed by an emerging perspective on education, learning and teaching that could act as a catalyst for re-invigorating the quality debate, by stimulating key processes in human development and social change at multiple levels, including the potential to enable children living in disempowering contexts to regain (or gain for the first time) some sense of identity and self-determination.

Transformative education (TE) consists of two fundamental steps: personal change and action. It is a process of recognising the structures of injustice and recognising one's own ability to redress those roots of injustice. Further, such transformation is not a one-off event but an ongoing process of continuous reflection and action, described by transformative educators as praxis. Although many elements of TE have originated within the area of adult education (Freire and Horton 1993; Mezirow 1990), the principles and pedagogies of transformation have worked their way into all domains of education, even at the basic and primary levels.

Transformative elements in education provide a strong counterpoint to universalistic visions of quality and fit more easily within a development paradigm that stresses contextualised, participatory processes. TE, being highly concerned with issues of power, requires a rethinking of the dynamics and practices in the classroom, expanding participation so that learning becomes a dialogical process, rather than students adopting an attitude and habit of passive powerlessness in the classroom. TE is designed to open up democratic spaces for participatory construction of curricula and learning outcomes. This not only encourages the engagement of students but can also heighten community participation, creating communitywide coalitions for learning and action regarding pressing local development issues.

As educational settings the world over are often burdened by racial, ethnic and gender barriers as well as those traumas and divisions present in violent and post-conflict situations - TE offers conceptual and methodological tools for helping children to surmount these internalised barriers and fault-lines. Such social cleavages disable development as surely as do illiteracy and innumeracy.

\section{Evidence for the contribution of TE in the formal school context}

The work of Cowhey (2006), hooks (1994), Sotto (1994) and Palmer (1993) demonstrates that a TE approach is fully compatible with highquality, formal educational contexts. Even at primary levels, there is evidence that the impacts of TE can be significant. Drawing on the two best known models of TE - the Escuela Nueva ${ }^{3}$ (EN) programme, which reaches more than 5 million children, and the Fe y Alegria (FyA $)^{4}$ programme, which reaches more than 800,000 - evidence so far suggests that these programmes have not only achieved goals of making students more socially conscious and engaged with their 
communities, but they have also enhanced cognitive development. This appears to make them effective not only from a humanist and transformative perspective but also in terms of the expectations associated with the behaviourist approach. Consequently, ardent supporters of an economistic approach, such as the World Bank, are long-standing supporters of these kinds of programmes, particularly Escuela Nueva.

What does a TE approach mean in practice? Here we present these experiences in relation to key educational stakeholders: children/learners, teachers, parents and policy- and decision-makers.

\subsection{Children/learners}

\subsubsection{The way children learn}

TE in formal settings presents a very different learning experience for students. Extremely successful transformative approaches, such as those used in the EN and FyA models, do not operate in traditional teacher-centred spaces with students aligned in forward-facing rows, but use child-centred classrooms. Rather than working as a single class, with everyone learning the same lesson at the same time and pace, classes are broken into small groupings of four or five students who work collaboratively on projects that have been assigned to them. Such scenarios allow flexibility in learning; this collective construction is important.

Furthermore, children are encouraged to think critically, to question in the classroom and beyond, to reflect on inconsistencies in what they have been taught and what they see happening in reality.

\subsubsection{What children learn}

In these schools, much of the curriculum is designed in conjunction with the local context. Learning programmes are designed to be carried beyond the classroom, into the home and community. As EN's President, Vicky Colbert, has said of the EN curriculum, 'anything the child learns has to be relevant and applied with the family and the community. That way, you ensure that the child becomes an agent of change in his or her family' (Nee 2008). Beyond the typical subjects, children are also encouraged to think about rights, ethics and cooperation. They learn about peace issues and expand on these ideas through role-plays that are performed in front of parents and communities to heighten awareness of the importance of these issues.

\subsubsection{Children's agency}

Outside the classroom, students are active in the life of the school. They are encouraged to form a student council and to make democratic choices about how to improve the school. The emphasis on connecting knowledge with community issues requires students to undertake learning projects beyond the school so that they can actively learn by investigating issues in their community. Encouraged to be agents of change to make their communities better, they may tackle important and unaddressed issues.

\subsection{Teachers}

\subsubsection{Teachers' engagement with the community}

The experience for teachers in transformative learning environments is also potentially empowering, opening up more spaces for creativity inside and outside the classroom as the experiences of EN and FyA show. In these transformative modes, one of the responsibilities of the teacher is to take the generalised teaching materials as a starting point, and to work with the community to contextualise them so that they relate better to the context and history of a particular location.

\subsubsection{Extending teaching methods and freedom to learn}

The non-conventional classroom arrangements mentioned earlier, which focus on group inquiry with teacher support, require a different mode of preparation and pedagogical methods from teachers. Instead of giving information directly to children, teachers encourage them to actively discover ideas and information and aggregate their collective knowledge to reach conclusions, rather than only expecting the 'answers' from the teacher. This shift will initially require effort and adjustment by teachers, but the benefit is more space for learning in the class as each group moves at its own pace and the teacher is more free to provide supervision to those who most need it.

\subsection{Parents}

\subsubsection{Greater participation in their child's education}

Transformative educators tend to draw on the cooperation, knowledge and experience of parents to help improve the quality of learning. Since TE programmes are designed around locally relevant knowledge and issues, with the curriculum partly designed by parents and the community, it is often the case that members of 
the community and parents can offer highly pertinent lessons relating to these curricula. It is not uncommon for parents to be invited into the classroom to teach about local issues. ${ }^{5}$

\subsubsection{Closer relationship with the school}

Parents' involvement in TE programmes can often go farther than this. In FyA schools, a parents' centre is built into the school itself, so that there is a space especially for them; this helps them to feel welcome at the school and encourages them to stay engaged with their children's learning process. TE schools are frequently multiple-purpose sites that may also provide adult education programmes, basic healthcare facilities and even microenterprise training. As such the school is a continual hub of activity, functioning as a community centre (Marshall and Keough 2004). With the confidence that not only will their children learn to read and write but also learn a viable trade, parents may be more convinced to keep their children in school until they have graduated with both intellectual and professional training, thus reducing dropout rates. There is no doubt that many parents of school-age children currently recognise the inadequacies of the education they receive and would wish for something better - as this comment from a school inspector in Zambia reveals:

Sending every child to school is good but if the education they receive is irrelevant to their needs and that of their society, then that education has no credibility and is therefore questionable. It's like sending all the sick to hospitals where they are given wrong medication for their ailments. Improving the infrastructure and maintaining excellent doctor/patient ratios alone, may not be enough. Such patients may even have side effects or be poisoned (Mwenya Musanshi 23/02/06. Group two). (Banda 2008)

\subsection{Policymakers and decision-makers \\ 5.4.1 Effective schools}

Policymakers find themselves under a great deal of pressure to achieve the goals set out by the EFA framework. TE models may help to provide an effective way to move students through the system more rapidly and more economically. Existing TE models have scored well both qualitatively and quantitatively. The EN model was recognised by the World Bank in 1989 as one of the best innovations in global development. The model has been praised for simultaneously addressing issues of efficiency, effectiveness, relevance and equity through changes in pedagogical processes at the classroom level rather than through significant changes at the other levels of the educational system (Kline 2002).

\subsubsection{Cost benefits and improved learning outcomes}

Though the EN approach can sometimes appear to cost more per child per year than the general government school system, more complex calculations by McGinn (1996) suggest EN is actually more cost effective because there is far less repetition in this programme than in the public model, thus making the transformative model cheaper over the lifetime of the student.

\section{How would TE address inequalities that are transmitted intergenerationally?}

Investing in TE approaches at the primary and secondary levels is a systemic investment in social change. TE encourages inclusion of locally relevant knowledge, which is more effective in facilitating change at the community level because it challenges the learner to put that knowledge to direct use. It also encourages the learner to be a conduit of that learning so that she or he may carry those ideas outward into their homes and communities, sharing ideas on health, nutrition and peace while also challenging conventional wisdom on gender stereotypes and other issues of social exclusion. The shifting relationship between school and community means that knowledge generated through this form of education does not remain bottled up within the school but can circulate throughout the community, stirring debate and catalysing change. Through this dynamic process of knowledge exchange, with new ideas continually permeating families and communities, TE may help to disrupt IGT processes by supporting collaborative learning and the spread of 'useful knowledge' within households and beyond.

The following are examples of TE's impact on community practices:

- Students in Monteverde, Costa Rica, when faced with a water shortage, and knowing that their community's economy is based on the preservation of their fragile cloud-forest environment, set up experiments to measure the amount of water each hotel in the 
community was using. They eventually listed their findings publicly to shame overconsumers into reducing their usage.

The National Curriculum Framework in India challenges students to think critically about the roles that women and men play in their communities and in their own families:

Show the class a picture of a household with various members of the family performing various tasks. The difference is the father is cooking, the mother fixing the light bulb, the daughter returning from school on a bicycle, and the son milking the cow ... the grandfather is sewing on a button and the grandmother is doing the accounts. Ask the children to talk about the picture ... Do they think that there is any work that these people should not be doing? Why? Involve them in a discussion on dignity of work, equality and gender. (Annaparra 2005)

- The Ganzu Basic Education Project is a largescale attempt by the Chinese government to meet the needs of marginalised rural minority students in Western China. Drawing on TE practices, the Ganzu Project pedagogy is built around child-centred, cooperative learning that promotes creativity and the development of the individual. The schools have been redesigned as 'children's schools' by working with the children themselves to design spaces and furniture that make them feel comfortable. Teachers have been recruited and trained especially for the project, with many female teachers brought in from other areas. The training has aimed to help teachers reconceptualise their relationships with the community and with students in more inclusionary ways. Teachers work closely with the communities to make the teaching materials relevant to local contexts and needs. Each of the schools has satellite links with the main project office, allowing for continual professional development training for the teachers as they share and learn from one another's experience in the project (Barrett $e t$ al. 2007)

\section{TE and systemic change}

Fundamentally, TE embeds education into the larger context of society. Too often the ends of education are perceived narrowly in purely individualist terms - high examination results, completion and higher wages. These are of course important, and reflect both needs and aspirations, but TE aims to bring broader learning outcomes for children and to widen their aspirations, beyond the individual to society at large. TE offers children a range of outcomes from their education.

- Cognitive development

- Emotional and social development

- New knowledge and skills

- Inclusion

- Attitudes and values that reflect human rights

- Ability to participate fully in classroom and school

- Connection between school, home and community

- Ability to think critically, to question and to act.

Furthermore, it begins with a social paradigm: groups of learners working cooperatively to answer questions, teams of students working to maintain their school, the entire school aiming to contribute positively to the life of the community, and communities linking to communities to share experience and strengthen cooperative ties. The active collectivity at the core of TE is generally seen to be at the core of civil society: people coming together over a common problem to decide on a collaborative response. TE begins to develop these skills with all students; thus not only building basic skills and enhancing cognitive development, but also helping students develop the core attributes of active citizenship that empower them to take action to improve the world they see around them through democratic processes. TE encourages wider social change by imbuing students with an inherent knowledge of their right to participate and have a voice in society. Where those pathways to citizenship are blocked or denied, they can draw upon the knowledge, skills and attitudes learned through schooling to help them realise their rights as constituents of a democratic system. TE helps to create empowered individuals who expect and will struggle to be fully empowered citizens

The following are recent examples of how TE programmes have helped youth to address issues of disempowerment and social exclusion:

- Students in Senegal, upon learning in their school that education is a human right, questioned why so many of their neighbours 
were not allowed to attend school. Finding out that children had to be registered with the government before they could attend, the students learned what was needed to register the other children, then collected the appropriate forms and canvassed door to door through the neighbourhood until the entire community was eligible to enrol - adding some 4,500 students to the school system (PDHRE 2007).

- Through Children's Clubs formed at Nepalese schools, students have become active campaigners to improve the quality of their education. They have held rallies to encourage enrolment of marginalised castes and spoken out against both caste and gender discrimination. When schoolteachers themselves have acted in a discriminatory manner, the clubs have taken public action and had the teachers censured. Some clubs have also become active in combating community practices of forced marriage and have intervened in cases where their classmates have been involved (Pradham 2008).

- The Education for Peace programme in Bosnia and Herzegovina brought together schools across ethnic groups and former battle lines to encourage students to take part in community theatre programmes that addressed specifically issues of the war, discrimination and distrust. Public performances of the student shows brought divided communities together for the first time since the conflict and provided a basis for dialogues on reconciliation (Clarke-Habibi 2005).

A variety of informal TE programmes have been successful in helping former child soldiers find ways of supporting one another. The PROPAZ programme in Mozambique helps former combatants reconcile across former battle lines and encourages them to help one another with processes of reintegration. Participants are also trained in mediation with a wider purpose of using their experiences to sensitise communities to the threat of future conflict. Since the beginning of the mediation campaign, PROPAZ participants have been responsible for the resolution of 347 documented local conflicts. ${ }^{6}$ Similarly, the Gulu Youth for Action (GYFA) group in Uganda has been created by female ex-combatants and works with former female soldiers to develop their leadership skills. GYFA members organise and educate in refugee camps to increase knowledge of human rights, mediation skills, gender-violence preventions and sexually transmitted infections. ${ }^{7}$

\section{- UNESCO and the United Nations High}

Commissioner for Refugees worked together to create the Peace Education Programme for use in refugee camps around the world. Currently implemented in 11 countries, the curriculum centres upon human rights learning. It is designed to encourage both cognitive and emotional development in children. The pedagogy is active, promotes creativity and is based largely on cooperative groupwork projects. Its success has been attributed to the participatory design process of the programme in which refugee children and families discussed the particular challenges of camp life and envisioned the kind of learning that would foster hope and excitement for children (Barrett et al. 2007).

\section{What is needed to bring about a change to a form of education that has transformative qualities?}

Although the array of evidence for the practical benefits of TE is still somewhat limited, the stories and programmes cited in this article do represent a significant body of achievement. In this article we have tried to demonstrate the extent to which TE can enable mainstream educational processes to take a fresh approach to ensuring quality for all children. We believe this can be achieved by building on the core aspects of existing quality approaches, while promoting greater agency in the classroom, school and wider community. Ultimately we see this as contributing more explicitly to the overarching development goals of human development and social change than can be achieved by either humanist or behaviourist/economistic approaches to education alone.

$\mathrm{TE}$ is not as foreign or as distant from mainstream discussions on quality as it might first appear, particularly in relation to the humanist approach for defining quality. It appears however that the humanist approach, favoured by the majority of civil society organisations (CSOs), is waning under the influence of a more behaviourist/economistic 


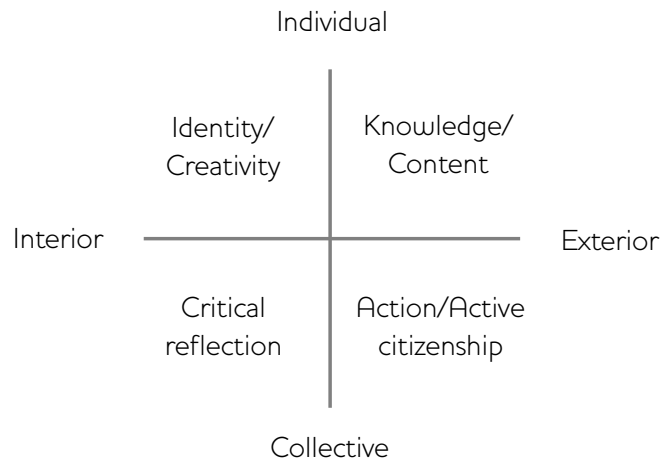

approach and its emphasis on quality as effectiveness. Supporters of the humanist approach need new ways to help bolster their position so that it does not become submerged under the weight of metrics and the logistics of testing and measurement. We believe that there is growing evidence for the potential of TE to bring a new but complementary dimension of educational quality and effectiveness that links directly with the larger aims of development as a whole as outlined in the current MDG framework. TE approaches can augment and even amplify many aims of the humanist approach. Combining the most valuable aspects of the behaviourist approach (understanding of cognitive processes and individual learning), coupled with a humanist understanding of quality education that is infused with transformative learning theory, could help to facilitate dynamic educational engagement with change and development processes at multiple levels.

In developing contexts - especially given that half of the world's out-of-school children live in fragile, conflict-ridden circumstances - the need for education to be extremely contextualised and relevant to daily life - and survival - is enormous (Taylor and Mulhall 2001). TE theory is born out of conflict, oppression and social movements. It is a form of education premised on difficult conditions and massive obstacles to positive change. If embedded within the 'quality in education' discourse as it applies to EFA, then quality would acquire dimensions more appropriate to its operative circumstances. It would thus provide educators and learners greater leeway to use the educative process as a pathway to emancipation and empowerment by learning to become active in changing their circumstance rather than waiting for others to take action on their behalf. Introducing TE into the classroom does not require a radical change of content or curriculum (although curricula do need to reflect children's interests, value locally relevant knowledge and skills, be nondiscriminatory and promote respect and understanding of rights) but does imply a change in process: more participation, more reflection, more critical analysis and more engagement with the realities just beyond the classroom.

Figure 1 attempts to synthesise the three approaches discussed in this article to create a suggested 'ideal' form of education.

The behaviourist approach is the upper right quadrant. This incorporates 'core' elements such as literacy and numeracy into the curriculum as central elements. Cognitive development remains a central aim, but content is appropriate for the situation rather than being purely examination driven. The upper left quadrant incorporates much of the humanist approach to education where learning is focused on students' personal growth and development through processes of freethinking and creativity.

Humanist and transformative approaches meet in the lower left quadrant. Humanist approaches, particularly those developed in conflict or postconflict situations have begun to look seriously at maintaining children's psychosocial health through their education, helping them to deal with emotional disturbances and perceptions of low self-worth (Marques and Bannon 2003). Such aspects link well with Mezirow's (1990) ideas of 'frames of reference' and his work of helping 
students peel away layers of constructed identities until they can begin to reframe and interpret their lives according to their own perceptions. This is a key moment where transformative education begins to move beyond either the behaviourist or the humanist approach. Whereas humanists would approach psychosocial healing as an individual process, transformative education looks on this as an individual and a collective endeavour in which, by sharing their experiences, students can help each other untangle their worldviews and reframe their psychological points of reference in the process. The collective approach then carries this reflective self-analytic process beyond the individual context into the larger social world and environment.

Finally, the lower right quadrant is unique to TE, as it envisions the outcome of education as action/active citizenship. After serious reflection and questioning, learners are encouraged to test their evolving worldviews outside the classroom by taking action, becoming active members of their community. In TE, action/active citizenship is the indicator of effectiveness because action verifies empowerment, the movement from passivity to engagement, the beginning of a transition from oppression to liberation. As was emphasised before, this is not a one-off event but a perpetual process fed by wider elements represented in each of these quadrants: flows of knowledge and reflection; strengthening identity and critical thinking; stimulating action on the wider environment.

If the educative process is to become a direct stimulus for individual and social change, and thus reforming education into both a long-term and a short-term investment by its supporters and resourcers, all three approaches to quality education for children and young people must be synthesised. This combination also helps to suggest avenues for exploration of pernicious and persistent dimensions of IGT of poverty, violence and disempowerment described in other articles in this IDS Bulletin. For example, by enabling boys 'trained' into violent behaviour in Jamaican inner cities (Gayle, in this IDS Bulletin) to experience a form of education that is grounded in both an individual and a collective dialogue and a disentangling of the many oppositional factors and internal insecurities that breed violence and conflict, change in their lives could become feasible. TE approaches could help to challenge fixed notions of masculinity while connecting them also to the wider social context (Greig, in this IDS Bulletin). New understandings and practices of educational quality could help to reverse the deficits experienced by boys in the schooling system in Bangladesh (Tariquzzaman and Hossain, in this IDS Bulletin). The development of understanding by young people of complex issues such as sexual and reproductive health (Edström and Khan, in this IDS Bulletin), which have both personal and social dimensions, could be approached through education in a way that is conscious of the advantages of different, targeted approaches, typified in the four 'quadrants' shown in Figure 1.

\section{Conclusion}

Through critical thinking and reflection, students make learning relevant; for themselves, for the issues which affect them and for their own contexts. TE animates autonomous social change through learning and is relevant even for young children. Learners take control of their own circumstances, as they learn to perceive how their power and field of action has been limited. Rather than being objects of educational goals, students become subjects of education, transforming their learning into a vital resource to meet their needs and achieve their objectives, thus transforming the educational sector into a tremendous motor for social change. The incorporation of TE into education policy and practice of quality has, therefore, the potential to disrupt existing patterns of IGT of poverty and social exclusion at the local community level, and nationally. It may also help to disrupt and change embedded, socially constructed pathways such as gender ideology and practice (Tadros, in this IDS Bulletin). There is strong evidence that by becoming actively engaged in their own schooling and their own learning, children can experience greater cognitive, emotional and social development. In the most challenging environments - those currently furthest from the MDG and EFA goals, including CAFS - children could finally have an opportunity to learn in a safe and supportive environment, where inclusion and respect for their rights will help them overcome experiences of trauma, displacement and social marginalisation. If experience is indeed a foundation for learning, then the children whose experience of education 
is transformative may have a real potential to move away from the knowledge of disempowerment and to become active, knowledgeable citizens - economically, socially and politically - of the future.

Achieving this is a challenge, however. Highquality education will always require resources, capacity development and system strengthening. The experiences and evidence described in this article suggest that achieving sufficient numbers of well-trained teachers, competent in and comfortable with TE methodology, is a key policy requirement. Change requires time but as international debates turn from access to intensifying efforts on quality, TE could be smoothly incorporated from the outset. While further investigation into $\mathrm{TE}$ in the formal school sector would be beneficial, evidence from non-formal youth and adult TE (Bivens et al. 2008), along with the documented limitations of current quality models are sufficiently compelling to suggest that TE should be part of future policy and practice on quality education. Even so, there seems to be underutilisation of the capacity of TE to amplify and accelerate the positive social impacts of education at all levels and ultimately to drive forward the wider processes of development by fostering engaged, critical participation of children in the classroom, their school and wider community.

\section{Notes}

1 Conflict-affected fragile states (CAFS) are a typology of countries defined by Save the Children (2007).

2 UNESCO Institute of Statistics (2008).

3 www.volvamos.org/.

4 www.feyalegria.org/.

\section{References}

Annaparra, D. (2005) 'New Curriculum Framework: A Few Chapters Short', India Together, www.indiatogether.org/2005/dec/ edu-ncf2005.htm (accessed 22 October 2008)

Banda, D. (2008) 'Education for All (EFA) and African Indigenous Knowledge Systems (AIKS): The Case of the Chewa People of Zambia', unpublished PhD thesis, University of Nottingham

Barrett A.; Ali, S.; Clegg, J.; Hinostroa, J.E.; Lowe, J.; Nikel, J.; Novelli, M.; Oduro, G.; Pillay, M. and Tikly, L. (2007) 'Initiatives to Improve the
Further research is needed to help us understand how TE approaches can augment learning at the school and classroom level. Based on evidence, it may then be possible to create and trial learning, networking and collaboration projects that introduce TE approaches into other schools, and to closely monitor and evaluate the impacts. It is important to explore how the approaches of primary- and secondary-level educators whose pedagogies are strongly transformative actually play out through education of children in different contexts, including those perceived as disempowering, to better understand the nuances and specificities of working transformatively with young students. There are some practical actions that could be tried and tested. For example, networking between TE practitioners could be encouraged to build a larger body of knowledge and practice, particularly at the early educational level. CSOs and other educational practitioners with experience in transformative approaches could be linked with schools to serve as consultants to help familiarise educators with the aims and practices of TE as a preliminary step to making TE more integral to EFA pedagogies. Ultimately, it is necessary that research should reveal more conclusively the extent to which TE can have a positive impact on current teaching and learning practices and the benefits that accrue to students, the community and wider society.

5 Escuela Nueva International homepage, www.eninternational.org/ (accessed 24 October 2008).

6 www.propaz.org.mz/.

7 www.comminit.com/en/node/132790 (accessed 24 October 2008).

Quality of Teaching and Learning: A Review of Recent Literature. EdQual', paper commissioned for the EFA Global Monitoring Report 2008, Education for All by 2015: Will We Make It? http://unesdoc.unesco.org/images/ 0015/001555/155504e.pdf (accessed 24 October 2008)

Bivens, F.; Okitsu, T.; Moriarty, V. and Taylor, P. (forthcoming, 2008) Quality Education for Transformation and Social Change, London: Save the Children, UK

Clarke-Habibi, S. (2005) 'Transforming Worldviews: The Case for Education for Peace 
in Bosnia and Herzegovina', Journal of Transformative Education 3.1, January: 33-56

Cowhey, M. (2006) Black Ants and Buddhists: Thinking Critically and Teaching Differently in the Primary Grades, Portland: Stenhouse

DFID (Department for International Development) (2008) 'Jobs, Skills and Shared Growth: Links, Constraints, Opportunities and Gaps', Policy Briefing, London: DFID

Dewey, J. (1916) Democracy and Education: An Introduction to the Philosophy of Education, New York: Macmillan

Freire, P. and Horton, M. (1993) We Make the Road by Walking: Conversations on Education and Social Change, Philadelphia: Temple University Press

Goldstein, H. (2004) 'Education for All: The Globalization of Learning Targets', Comparative Education 40.1

Hanushek, E.A. and Wößmann, L. (2007) Education Quality and Economic Growth, Washington DC: World Bank

hooks, b. (1994) Teaching to Transgress. Education as the Practice of Freedom, London: Routledge

Kline, R. (2002) 'A Model for Improving Rural Schools: Escuela Nueva in Colombia and Guatemala', Current Issues in Comparative Education 22.2, Teachers College, Columbia University, www.tc.columbia.edu/CICE/ Archives/2.2/22kline.pdf (accessed 22 October 2008)

Marques, J. and Bannon, I. (2003) Central America: Education Reform in a Post-Conflict Setting, Opportunities and Challenges, CPR Working Papers 4, Washington DC: Social Development Department, Environmentally and Socially Sustainable Development Network, World Bank

Marshall, K. and Keough, L. (2004) Mind, Heart, and Soul in the Fight Against Poverty: In The Fight Against Poverty, Washington DC: World Bank

McGinn, N. (1996) 'Requirements for Capacity Building: Escuela Nueva in Colombia', mimeo, study conducted for the Colombian Ministry of National Education

Mezirow, J. (ed.) (1990) Fostering Critical Reflection in Adulthood: A Guide to Transformative and Emancipatory Learning, San Francisco: Jossey-Bass
Moncrieffe, J. (2004) 'The Paradox of Social Exclusion/Inclusion in Jamaica', in C. JonesFiner and P. Smyth (eds), Social Policy and the Commonwealth, Basingstoke: Palgrave/Macmillan

Nee, E. (2008) ' 15 Minutes with Vicky Colbert: SSIR Managing Editor Eric Nee Spoke with Escuela Nueva's President Vicky Colbert About Her Efforts to Change the Way Children are Educated', Stanford Social Innovation Review, www.eninternational.org/documents/ SSIRArticleVickyColbert.pdf (22 October 2008)

Palmer, P. (1993) To Know as We Are Known: Education as Spiritual Journey, New York: HarperCollins

PDHRE (Peoples' Movement for Human Rights Learning) (2007) Human Rights Learning: A Peoples'Report, PDHRE, www.pdhre.org/report/ (accessed 22 October 2008)

Piaget, J. (1955) The Child's Construction of Reality, London: Routledge and Kegan Paul

Pradham, L.M. (2008) 'Children's Glubs: A Forum for Children's Active Participation as Change Agents', Education Action 22, London: ActionAid

Save the Children (2008) Last in Line, Last in School: How Donors can Support Education for Children Affected by Conflict and Emergencies, London: International Save the Children Alliance

Save the Children (2007) Last in Line, Last in School: How Donors are Failing Children in Conflict-affected Fragile States, London: International Save the Children Alliance

Sotto, E. (1994) When Teaching Becomes Learning: A Theory and Practice of Teaching, London: Continuum

Taylor, P. and Fransman, J. (2004) Learning and Teaching Participation: Exploring the Role of Higher Learning Institutions as Agents of Development and Social Change, Working Paper 219, Brighton: IDS

Taylor, P. and Mulhall, A. (2001) 'Linking Learning Environments Through Agricultural Experience - Enhancing the Learning Process in Rural Primary Schools', International Journal of Educational Development 21: 135-48 